\title{
CFD Simulation of the Flow Patterns and Structure Optimization within a Continued-Flow Integrated Biological Reactor
}

\author{
Xiejuan Lu', Zhenxing Zhong, ${ }^{1,2 *}$, Yu Cai ${ }^{3}$, Hui Chen ${ }^{1}$, Xiong Lan ${ }^{4}$, Chenxi Huang ${ }^{1}$, \\ Jingcheng Zhou ${ }^{5 * *}$, Fugang Zhang ${ }^{6}$, Beiping Zhang ${ }^{1}$ \\ ${ }^{1}$ School of Environmental Science and Engineering, Huazhong University of Science and Technology, \\ Wuhan, 430074, China \\ ${ }^{2}$ College of Environmental Engineering, Wuhan Textile University, Wuhan, 430200, China \\ ${ }^{3}$ Construction Project Management Center of Jiang'an District, Wuhan, 430070, China \\ ${ }^{4}$ Wuhan Planning \& Design Co., LTD, Wuhan, 430070, China \\ ${ }^{5}$ School of Information and Safety Engineering, Zhongnan University of Economics and Law, 430073, China \\ ${ }^{6}$ Three Gorges Base Development, Co. Ltd, Yichang, Hubei 443002, PR China
}

Received: 12 January 2021

Accepted: 14 May 2021

\begin{abstract}
The fluid patterns and structure optimization of a novel continued-flow integrated biological reactor (CIBR) were explored by using the computational fluid dynamics (CFD). The results of the CFD simulation revealed that both the liquid velocity field and the gas volume fraction in the CIBR showed an axisymmetric spatial distribution. Furthermore, increasing the aperture sizes of below diversion holes from $2 \mathrm{~cm}$ to $8 \mathrm{~cm}$ could significantly enhance the turbulent kinetic energy of three-phase separation zone. Consequently, the solid-liquid separation and the treatment efficiency of CIBR were enhanced. In addition, an increase in the angle of the inclined plate (from $35^{\circ}$ to $45^{\circ}$ and further to $50^{\circ}$ ) caused increases in the liquid velocity, volatility and gas holdup in the threephase separation zone, while decreased gradually in the settling zone. These changes improved gasliquid separation in the three-phase separation zone and the sludge sedimentation in the settling zone. The findings of the study provide an insight into the fluid characteristics of gas-liquid-solid three phases within the CIBR.
\end{abstract}

Keywords: computational fluid dynamics (CFD), simulation, continued-flow integrated biological reactor (CIBR), flow pattern, structure optimization

\footnotetext{
*e-mail: xing2006z@163.com

**e-mail: jingchengzjc@zuel.edu.cn
} 


\section{Introduction}

Computational Fluid Dynamics (CFD) is capable of conducting numerical simulation analysis and creating visual displays to describe fluid flow, heat transfer and other related physical phenomena. Under the control of three equations of conservation: those of mass, momentum and energy, the numerical simulations of flow state are conducted by CFD. Based on the discretization method, the discontinuous time and space are used to replace the continuous time and space. Subsequently, the partial differential of the conservation equation is transformed into an algebraic equation, and can be solved via a computer [1]. Consequently, many shortcomings of experiments and theoretical analysis could be overcome. Therefore, CFD is widely used in various flow field studies as it is a low-cost, shortterm and high efficiency method for obtaining the data during the flow field [2].

CFD is a powerful tool which allows studying the influences of the operating parameters and the phenomena at a local scale [3]. As for water treatment reactors or industrial structures, CFD is mainly applied to simulate the flow patterns, optimize the internal structures and analyze operational conditions of the reactor. Gresch et al. studied the internal flow field of the aeration tank under different aeration modes using the CFD simulation, and found that small changes of the aeration mode imposed a drastic difference on the overall flow field [4]. To optimize the aeration efficiency of the activated sludge processes, Fayolle et al. used CFD to simulate flow characteristics and oxygen transfer in four aeration tanks of different sizes. Following this, the data of the axial liquid velocity, the local gas holdup and the oxygen transfer coefficient were measured, computed, and compared. The oxygen transfer coefficient was precisely reproduced with an accuracy of 5\% [5]. Johnson et al. used CFD to analyze five bioreactor configurations to evaluate energy dissipation rates and Kolmogorov length scale distributions at various scales. The results showed that hydrodynamic scalability was achievable and the mean Kolmogorov length scale was substantially higher than the average cell size [6]. Similarly, Shahrokhi et al. also used CFD to analyze the influences of different baffle positions on the flow state of the primary sedimentation tank from the hydraulics, and the reliability of the simulation results were verified by the flow velocity experimental results measured by Doppler velocimeter [7].

A novel continued-flow integrated biological reactor (CIBR) was designed to be an efficient and integrated reactor for the removal of organic matter, nitrogen and phosphorus in sewage wastewater. A CIBR can operate continuously for wastewater treatment, in which simultaneous removal of carbon, nitrogen and phosphorus occurs. Furthermore, it also decreases the operation cost of pumps for returned sludge. Studies about the running processes, reaction mechanisms, biochemical reaction model, online control and bacterial communities in a CIBR have already been conducted in recent years [8-11]. However, in regards to the actual operation of CIBR, there are few questions sought to be settled, such as dead-zones and the low separation efficiency of gas-liquid-solid in the three-phase separator. Meanwhile, a small amount of gas could run into the sedimentation zone, which affects the reaction efficiency of the reactor. In addition, the hydraulic flow characteristics and mixed state also affects the reaction efficiency and the sedimentation of sludge.

To further enhance the removal efficiency of the CIBR, a CFD model with adjustable parameters was firstly developed to demonstrate the internal flow patterns, Then, the developed model was applied to optimize the size of the below diversion hole and the angle of inclined plate in the three-phase separation zone of the CIBR.

\section{Material and Methods}

\section{CIBR Reactor}

The schematic diagram of the CIBR system is shown in Fig. 1. The CIBR was made of plexiglass (thickness is $10 \mathrm{~mm}$ ) and consisted of three parts: a reaction zone, a three-phase separation zone and a settling zone. The plane sizes of reactor and biological reaction zone were $658 \times 982 \mathrm{~mm}$ and $608 \times 608 \mathrm{~mm}$, respectively, and the plane size of settling zone in double side was $608 \times 137 \mathrm{~mm}$. The height of bioreactor was $1000 \mathrm{~mm}$ and the effective depth was $900 \mathrm{~mm}$, and the effective volume of bioreactor was $0.37 \mathrm{~m}^{3}$. The mounting angle of the inclined plate of the three-phase separation zone was $35^{\circ}$. Three aeration pipes were installed in the bottom of the reaction zone and a stirring paddle was installed in the center of the reaction zone.

In the biological reaction zone, aeration (oxic condition) was achieved using an air pump and agitation (anoxic condition) was achieved using a mechanical mixer. The air pump and mixer were operated alternately by a microcomputer switch. In contrast, the anaerobic condition could be achieved when both the air pump and mechanical mixer were stopped and the sludge settling period began. The reaction zone and the settling zone were connected by the threephase separation zone, and the treated mixed liquor with gas flowed into the three-phase separation zone, in which gas, liquid, and activated sludge were effectively separated. Then, the sludge returned to the biological reaction zone with the continuous accumulation of sludge, and the gas spread out via the gas pore to avoid any effects on the sludge-water separation process. The supernatant flowed out through the overflow weir at the top of the settling zone. 


\section{Simplification of the Flow Pattern Simulation Model of the CIBR}

\section{Selection of the Model Dimension}

A CFD model was employed to predict the flow pattern and gas hold-up. The CFD model was developed by using the 15.0 version of a commercial CFD code FLUENT (ANSYS, Inc., Pennsylvania, USA). In order to simplify the model, the occupied space of the stirring paddle within the reactor was ignored during the simulation of two-phase flow. Meanwhile, the aeration pipes were considered as one aeration tube, and the connecting portions between the aeration pipes were ignored, so that each vertical sectional view of the reactor was the same and the reactor can be simulated with the two-dimensional model.

\section{Setup of the Aeration Microspores and the Water Inlet}

The basis on the features of the aeration pipe, the average pore size of microspores on the aeration pipe was set to $1 \mathrm{~mm}$, the aggregation and rupture of the gas bubbles were ignored. In addition, the water flow entered the reactor through the capillary tube with a diameter of $6 \mathrm{~mm}$ from the upper surface. The upper surface of the reactor was divided into three parts, the water inlet is in the middle and a gas outlet was installed on both sides, since only one surface just can be set a boundary condition. The simplified structure size (mm) of CIBR is shown in Fig. 1b).

\section{Selection of the Turbulence Model}

During the actual operation, the flow status in the aeration process of the CIBR was composed of a three-phase gas-liquid-solid system. The density of the mixed fluid containing the activated sludge was
$1005.9 \mathrm{~kg} / \mathrm{m}^{3}$, showing little difference with the density of water, so the activated sludge system and water can be approximated in the liquid phase. Hence, the gasliquid two phase flow model of the CIBR in the aeration status was established with the Euler multiphase flow model and the dispersed turbulence model of standard $k-\varepsilon$ model by CFD simulation software. During the process of the numerical simulation of flow pattern, compared to the liquid, the gas volume fractions, were very small; accordingly, the standard k- $\varepsilon$ model of the dispersed turbulence model was selected [12-13].

\section{Division of the Mesh}

Due to the complexity of the three-phase separator of CIBR, it was difficult to divide the entire reactor into numerous meshes using only a single type of mesh. To deal with this difficulty, the partition method was applied to divide the entire reactor into three regions: a reaction zone, a sedimentation zone, and a three-phase separation zone. The structured quadrilateral mesh unit and Map types were used to divide the reaction zone and the sedimentation zone. The unstructured triangular mesh unit and Pave types were used to divide the three-phase separator and the binding zone of sedimentation and three-phase separation. Topical encryption technology was used to treat the meshes on the wall while the meshes were changed by exponential function.

\section{The Boundary Conditions}

\section{The Boundary Conditions of the Inlet}

The velocity inlet boundary was applied to the inlet of gas and liquid, while the inlet turbulent boundary conditions were presented by the turbulence intensity and hydraulic diameter.

\section{b)}

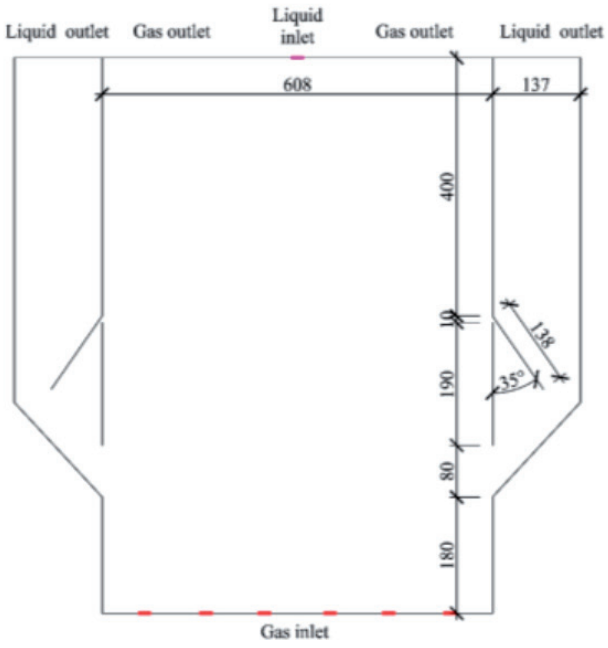

Fig. 1. The schematic diagram a) and the simplified structure size b) of the CIBR. 


\section{The Boundary Conditions of the Outlet}

The velocity outlet boundary was also used for the outlet of the sedimentation zone and thus the backflow at the outlet can be avoided. The top of the CIBR reaction zone was set as the degassing boundary condition, and the degassing boundary condition was the outlet boundary for gas and the symmetrical boundary for liquid. Setting the boundary conditions in this manner guaranteed the passage of gas and not liquid. The degassing boundary condition was added by a user-defined function.

\section{The Boundary Conditions of the Wall Surface}

The gas-liquid interface was set as the non-shear wall surface so that the normal velocity of the gas and liquid phase was automatically zero at the interface. Gas escaping was simulated through the mass sinks under the degassing boundary condition. Similarly, the movements of gas and liquid were simulated through the momentum sinks of the gas and the liquid. Other wall surfaces were set as fixed wall surfaces and the near-wall regions were treated by using the standard wall function method.

\section{The Simulation of Residence Time Distribution}

The simulation of residence time distribution of the CIBR was explored by a tracer test in the laboratory $\mathrm{CIBR}$ device, and the $\mathrm{NaCl}$ was used as the tracer. During the process of the tracer test of the CIBR, the structural parameters and operational conditions of the reactor are as follows: (1) the effective volume of the reaction zone of the CIBR was $0.37 \mathrm{~m}^{3}$, the effective volume of the settling zone and three-phase separation zone was $0.04 \mathrm{~m}^{3}$, the total effective volume of the reactor was $0.45 \mathrm{~m}^{3}$, the influent flow was $0.104 \times 10^{-4} \mathrm{~m}^{3} / \mathrm{s}$ and the tracer dosage were $200 \mathrm{~g}$; (2) the theoretical hydraulic retention time (HRT) of the reaction zone of the CIBR was $10 \mathrm{~h}$ and the theoretical HRT of the settling zone was $2 \mathrm{~h}$. The run time of the tracer test is usually 2-3 times of the length of the theoretical HRT. The reactor was continuously operated for $24 \mathrm{~h}$ and the water sample was collected to measure the electrical conductivity at intervals of $1 / 25-1 / 50$ of the theoretical HRT.

\section{Results and Discussion}

\section{Characteristics of the Flow Pattern in the CIBR}

\section{The Velocity Field in the Reaction Zone of the CIBR}

The vector graphics of the liquid velocity and the gas velocity in the CIBR are shown in Fig. 2. It is clear that both the velocity fields of the liquid and the gas presented a vortex structure flow state in the biological reaction zone, and that the velocity was upward at the center and was downward near the wall (Fig. 2(a-b)). a) The vector graphics of liquid velocity
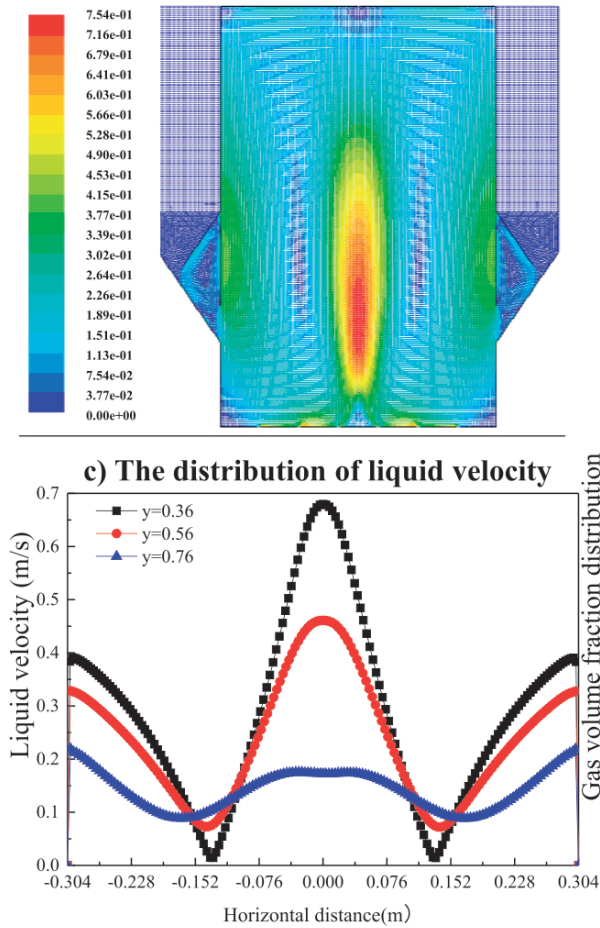

b) The vector graphics of gas velocity
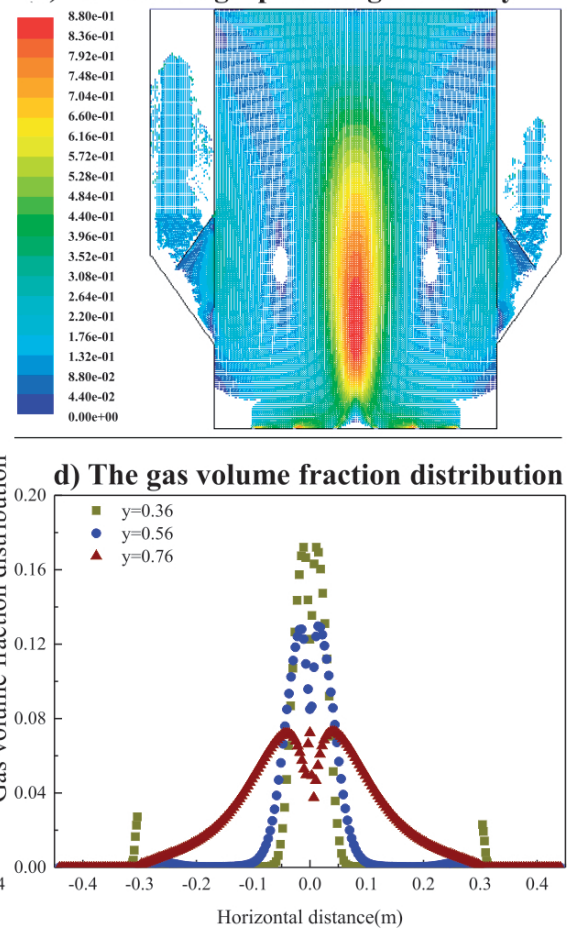

Fig. 2. The vector graphics of liquid velocity a) and gas velocity b) in the reaction zone, the liquid velocity distribution c) and the gas volume fraction distribution d) in the three cross sections in the CIBR. 
When aeration began, the gas rose at a low speed under the resistance of the liquid. The gas coming out of the aeration pipe gradually converged to the center of CIBR due to the mutual induction between the airflow. Thereafter, the resistance of liquid decreased and then the gas velocity increased. Driven by the upwelling airflow, the liquid at the center also moved upward, and flowed back at the inner wall of the reactor [14]. The gas in the reactor also formed a circulation, driven by a reflux liquid. In addition, two dead zones emerged as a result of the small impact of airflow.

At various vertical heights, three cross sections located at the distance of $0.36 \mathrm{~m}, 0.56 \mathrm{~m}$ and $0.76 \mathrm{~m}$ from the bottom of the reactor were selected to explore the distribution graph of the liquid velocity (Fig. 2c). It should be noted that the liquid velocity field of the CIBR had an axisymmetric spatial distribution pattern. The liquid velocity near the wall is zero, while the profile of the velocity is $\mathrm{W}$-shaped in the transverse direction of the reaction zone. The change in the velocity direction indicates a reflux occurring.

At various radial heights, the gas volume fraction also presented an axisymmetric distribution in the spatial pattern at the three cross sections located at $0.36 \mathrm{~m}, 0.56 \mathrm{~m}$ and $0.76 \mathrm{~m}$ from the bottom. And in the central region of the biological reaction zone, the gas volume fraction decreased gradually along the longitudinal direction (Y axis) (Fig. 2d). Meanwhile,

a) Liquid velocity in the three-phase zone

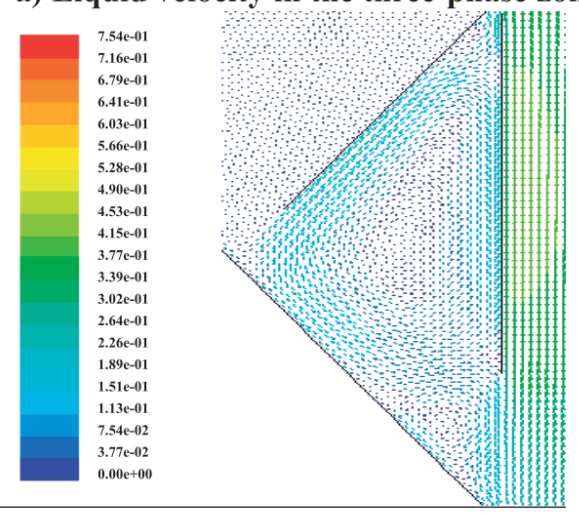

c) The cloud diagram of pressure

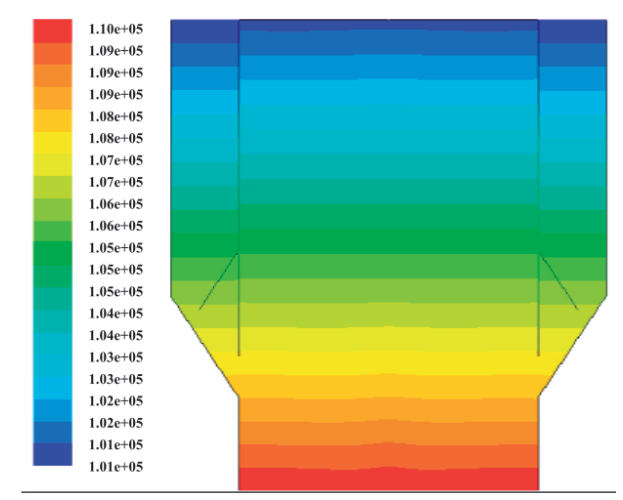

on both sides of the biological reaction zone, the gas volume fraction increased gradually along the longitudinal surface. The nearer the gas was to the surface of the biological reactor, the flatter its distribution became. The reason for this is that when bubbles went up in the longitudinal direction, they were less affected by the incident airflow [15]. Furthermore, the speed of the gas slowed down gradually as it traveled toward the surface, and the probability of its distribution moving laterally to both sides of the container increased, thus the distribution of gascontaining rates tended to flatten. The gas content in the three-phase separation zone was relatively high, which led to a small amount of gas entering into the settling zone. As a result, this could affect the sludge-water separation process.

\section{The Liquid Velocity Distribution in the Three-Phase Separation Zone and Settling Zone}

As shown in Fig. 3a), the liquid velocity distribution exhibited a vortex structure in the three-phase separation zone of the CIBR. During the aeration phase, some air got into the three-phase separator through the below diversion hole. The air moved upward, which also drove the liquid upwards. Meanwhile, the incoming air produced a density differential in the vertical level, which enhanced the circulation phenomenon of d) Liquid velocity in the settling zone

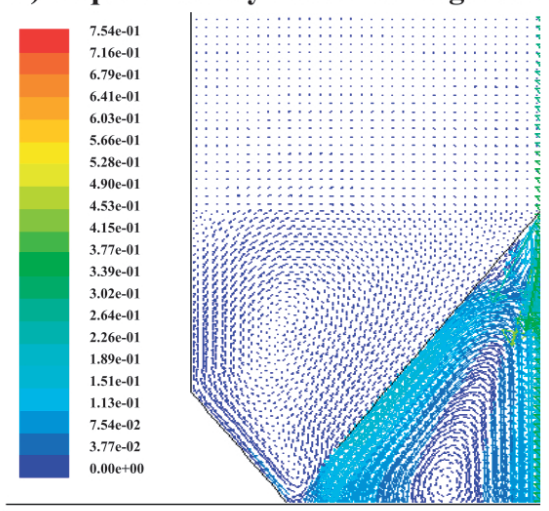

d) The liquid turbulent kinetic energy $\mathrm{k}$

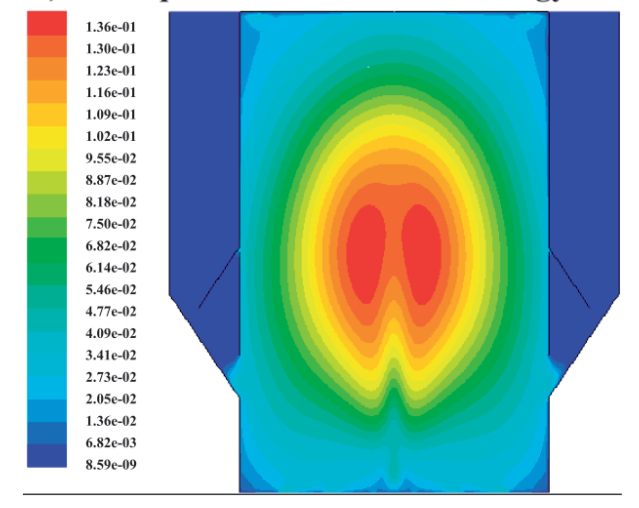

Fig. 3. The liquid velocity distribution in the three-phase separation zone a) and in the settling zone b), the distribution of cloud diagram of pressure c) and the liquid turbulent kinetic energy $\mathrm{k} d$ ) in the CIBR. 
the liquid in the three-phase separation zone. Some liquid entered the three-phase separation zone through the up diversion hole due to the circulation in the biological reaction zone, which manifested as a circulation within the three-phase separation zone.

Fig. 3b) shows that the liquid velocity in the settling zone of the CIBR was mainly composed of two parts. The velocity field at the bottom presented a vortex structure, which may be ascributed to a small amount of gas entering the area through the up diversion hole, consequently producing a circulation [15]. However, the liquid velocity at the top was relatively uniform and was less affected by the airflow. Furthermore, the liquid moved vertically upward and exhibited a laminar flow state [16].

\section{The Pressure Field in the CIBR}

Fig. 3c) shows a cloud diagram of the pressure distribution in the CIBR. It can be seen that the pressure changed slightly in the transverse direction, but decreased gradually from the bottom to the top of the bioreactor, and generally showed a gradual linear relationship in the vertical direction. In contrast, the fluctuation of pressure in the reaction zone was larger than that of settling zone due to the aeration influence [17]. Moreover, the movement of bubbles in the reaction zone led to turbulent phenomena, consequently, the pressure showed a certain fluctuation. However, the volume of gas entering into the settling zone was very small, and thus the pressure distribution therein was relatively uniform.

\section{The Turbulence Intensity in the CIBR}

Fig. 3d) illustrates the distribution of liquid turbulent kinetic energy, $\mathrm{k}$, in the CIBR. Similar to the velocity distribution, the turbulent kinetic energy of liquid exhibited a symmetrical distribution along the central axis. In the circulation region of liquid, the turbulent kinetic energy was relatively large and the turbulence was relatively strong. However, the turbulence was relatively weak in other regions. In particular, the turbulence of the liquid was very small in the settling zone and was approximated as a laminar flow [18]. As a result, the small amount of liquid turbulence favored the separation of activated sludge from mixed liquid.

\section{The Effects of Different Sizes of Below Diversion Hole on the Flow Pattern of the CIBR}

In the previous experiments, it was often found that the sludge tended to cluster in the three-phase separation zone of the CIBR, and the speed of sludge returned to reaction zone was very slow. Therefore, the influence of the size of the below diversion hole on the flow pattern of the CIBR was studied.

The velocity of liquid phase in three-phase separation zone was explored for diversion hole sizes of $2 \mathrm{~cm}$ and $8 \mathrm{~cm}$ (Fig. 4). From Fig. 4(a-b), the resultant liquid velocity corresponding to the $8 \mathrm{~cm}$ below diversion hole $\left(3.77 \times 10^{-2}-2.64 \times 10^{-1} \mathrm{~m}^{3} / \mathrm{s}\right)$ was generally higher than that of the $2 \mathrm{~cm}$ hole $\left(4.54 \times 10^{-7}-1.16 \times 10^{-1} \mathrm{~m}^{3} / \mathrm{s}\right)$. The contours of turbulent kinetic energy distribution a) $2 \mathrm{~cm}$
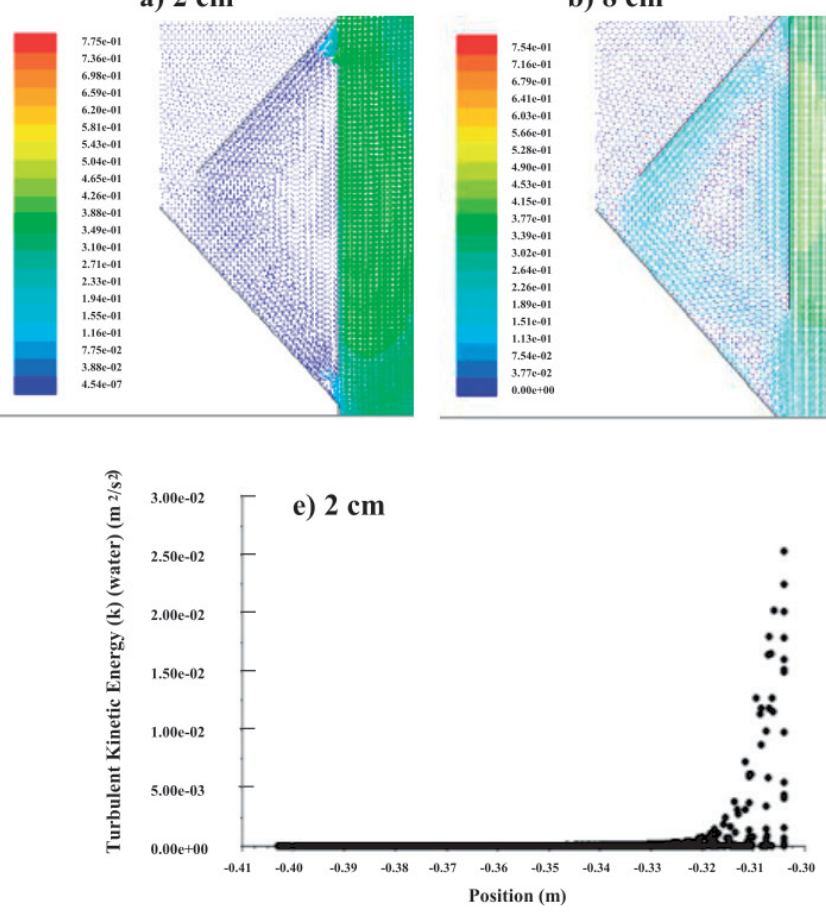

c) $2 \mathrm{~cm}$

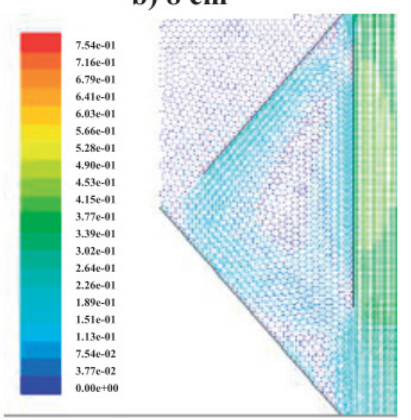

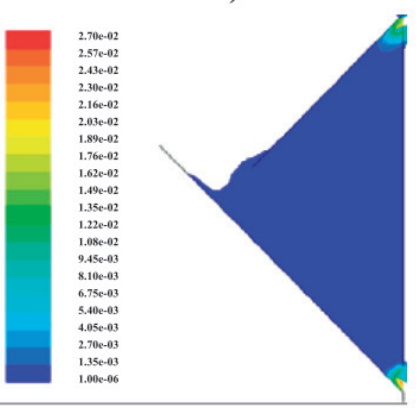

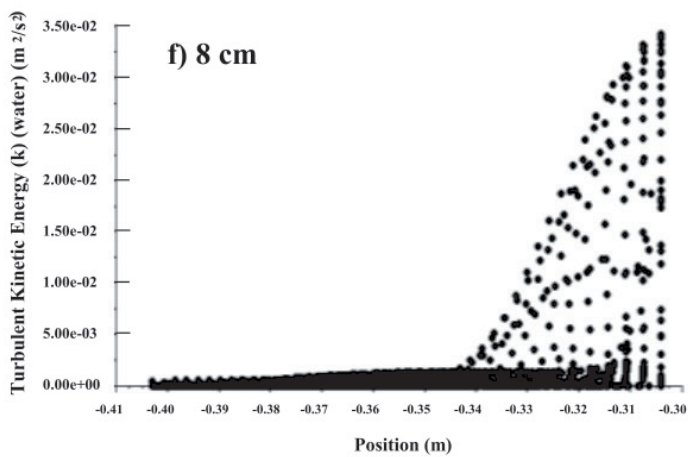

Fig. 4. The velocity magnitude of liquid phase (a-b), contours of turbulent kinetic energy distribution (c-d), and the scatter plot of turbulent kinetic energy distribution (e-f) under the sizes of the below diversion hole of $2 \mathrm{~cm}$ and $8 \mathrm{~cm}$, respectively. 
in the three-phase separation zone with the different hole sizes are shown in Fig. 4(c-d), and the corresponding scatter plots of turbulent kinetic energy distribution are presented in Fig. 4(e-f). As shown in Fig. 4(c-f), the turbulent kinetic energy of the below diversion hole with an $8 \mathrm{~cm}$ aperture was higher than that of the $2 \mathrm{~cm}$ aperture. However, the lower liquid velocity and turbulent kinetic energy exacerbated the formation of the death cycle in the three-phase separation zone, which was unfavorable for the separation of the gassolid-liquid phases [19-20]. As a result, the sludge was gathered in the three-phase separation zone and even formed anaerobic condition in actual operation. Finally, sludge bulking could occur, suggesting that the removal efficiency may become worse. Therefore, an increase in the size of the below diversion hole is beneficial for the increase in the turbulent kinetic energy, which could enhance the removal of pollutants by improving the solid-liquid separation in the reactor.

\section{The Efects of Three Different Angle of Inclined Plate on the Flow Pattern of the CIBR}

The influences of three different angles (35 degrees, 45 degrees, and 50 degrees) of an inclined plate on the flow pattern and the gas-liquid separation were simulated. Fig. 5(a-c) shows the contours for liquid phase velocity at the different angles.

Although the different angles of the inclined plate had no apparent effect on the flow pattern of the reaction zone, the liquid velocities of the threephase separation zone were significantly affected. It is obvious that the liquid velocity corresponding to the $35^{\circ}\left(0-2.26 \times 10^{-1} \mathrm{~m}^{3} / \mathrm{s}\right)$ was higher than those of $45^{\circ}$ $\left(0-1.34 \times 10^{-1} \mathrm{~m}^{3} / \mathrm{s}\right)$ and $50^{\circ}\left(0-1.34 \times 10^{-1} \mathrm{~m}^{3} / \mathrm{s}\right)$ within the three-phase separation zone. However, the high velocity of the liquid phase had a negative effect on gas-liquid separation in the three-phase separation zone.

Fig. 5(d-f) shows the velocity contours of the gas phase at three angles. It can be seen that the different angles of the inclined plate had a small effect on the gas distribution in the reaction zone. Nevertheless, the gas in the three-phase separation zone more easily entered into the settling zone with a $35^{\circ}$ incline for the plate. Moreover, two cross-sections were selected to compare the liquid velocity and gas volume fraction at $y=0.36 \mathrm{~m}$ and $0.46 \mathrm{~m}$ in the three-phase separation zone and the settling zone, respectively. The liquid velocity and the gas volume fraction were further compared at different angles. As shown in Fig. 6a), the liquid velocity and fluctuation corresponding to the $35^{\circ}$ plate were larger than those of the two other angles in the three-phase separation zone. However, the large liquid velocity was unfavorable for the separation of the gas from the liquid. From Fig. 6b), it can be seen that the liquid velocity of the settling zone under the angle of $35^{\circ}$ was larger than those of the other two angles. In particular, the velocity was affected significantly by the gas flow and the liquid of the three-phase separation zone, and the high liquid velocity of the settling zone a) $\theta=35$

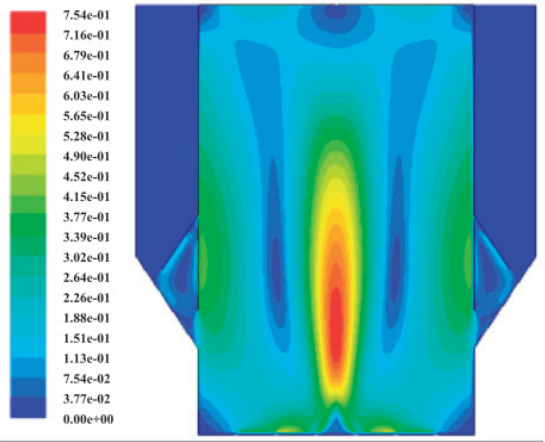

d) $\theta=35$

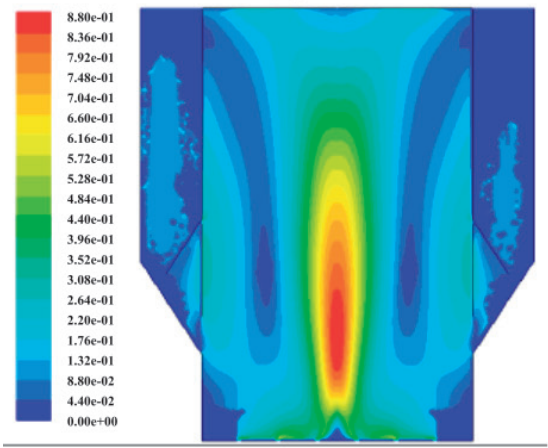

b) $\theta=45$

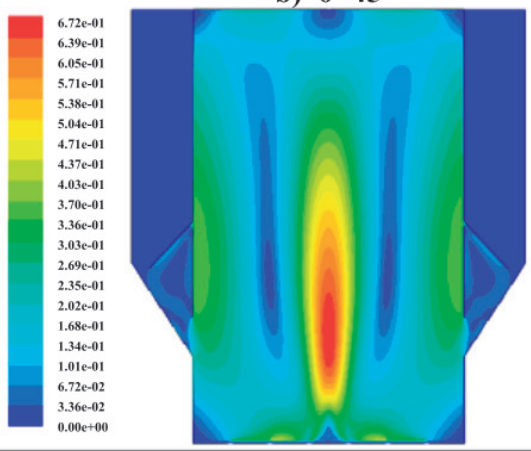

e) $\theta=45$

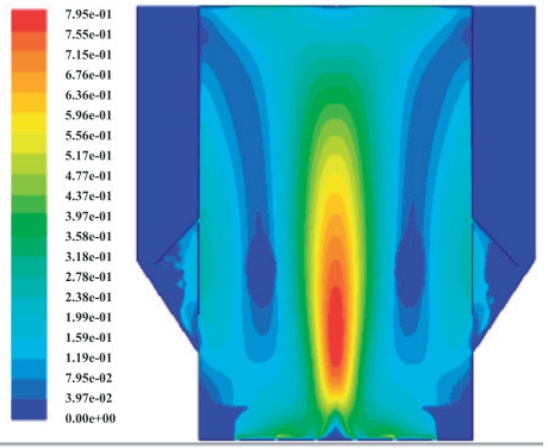

c) $\boldsymbol{\theta}=\mathbf{5 0}$

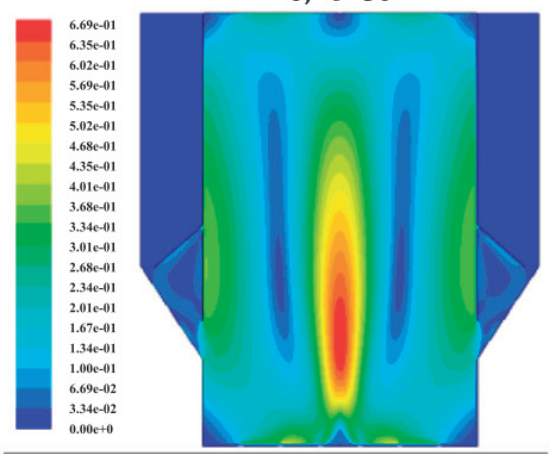

f) $\boldsymbol{\theta}=\mathbf{5 0}$

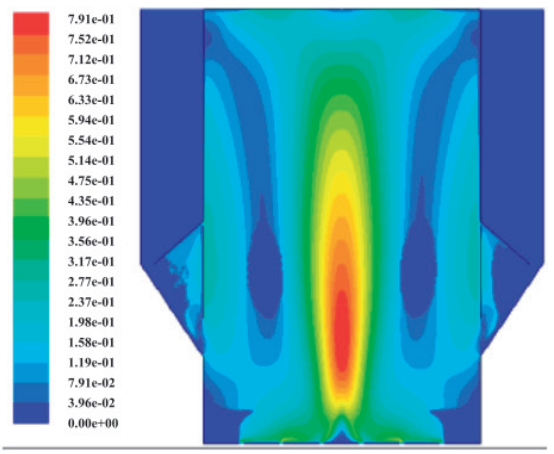

Fig. 5. Contours of velocity magnitude of liquid phase (a-c) and gas phase (d-f) when the angles of the inclined plate of CIBR are $35^{\circ}$, $45^{\circ}$, and $50^{\circ}$, respectively. 
a) $y=0.36 \mathrm{~m}$

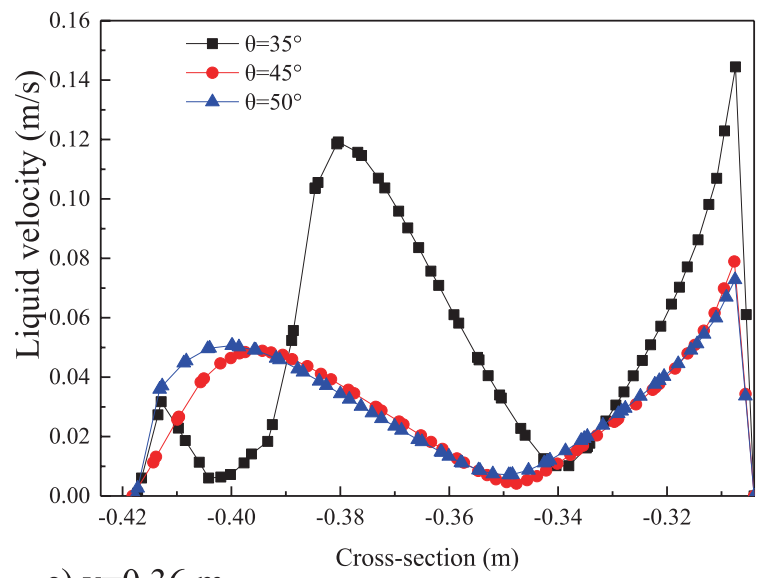

c) $y=0.36 \mathrm{~m}$

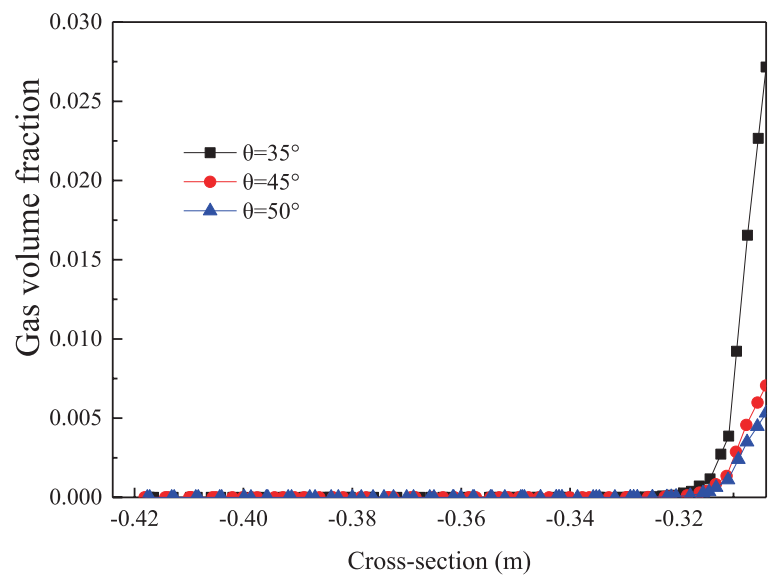

b) $y=0.46 \mathrm{~m}$

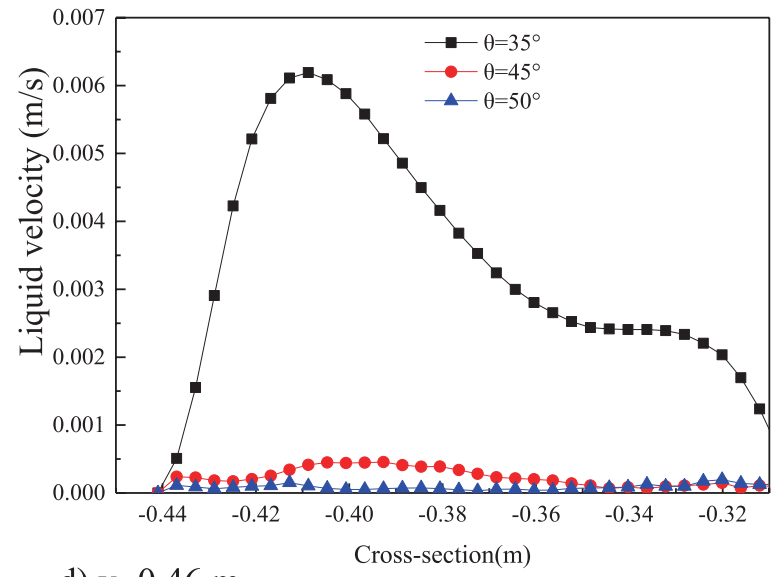

d) $y=0.46 \mathrm{~m}$

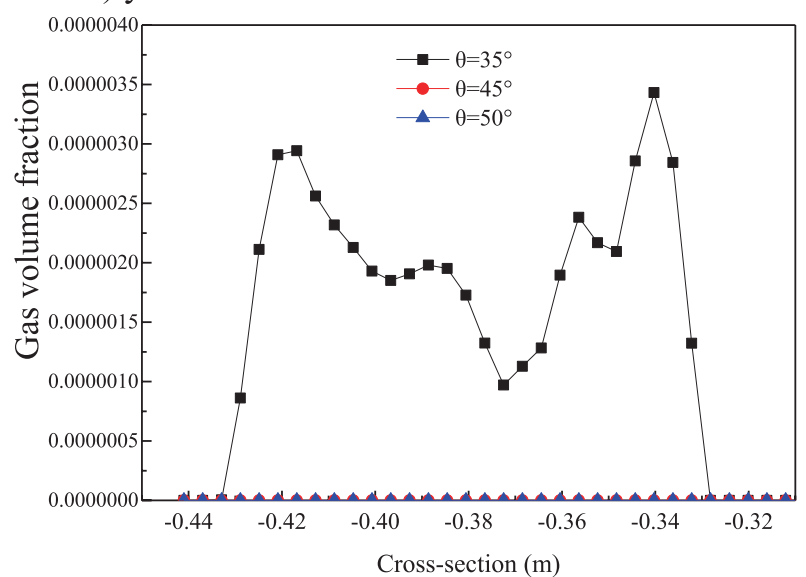

Fig. 6. The liquid velocity (a-b) and the gas volume fraction (c-d) at the same cross-section $(\mathrm{y}=0.36 \mathrm{~m}$ and $0.46 \mathrm{~m}$, respectively) of the different angles of the inclined plate.

was unfavorable for the sedimentation of activated sludge and particles [19].

The gas volume fractions in the settling zone and the three-phase separation zone were significantly higher with a plate angle of $35^{\circ}\left(0-2.7 \times 10^{-2}, 0 \sim 3.4 \times 10^{-6}\right)$ relative to the other two angles of $45^{\circ}\left(0-7 \times 10^{-3}, 0\right)$ and $50^{\circ}\left(0-5 \times 10^{-3}, 0\right)$ (Fig. $\left.6(\mathrm{c}-\mathrm{d})\right)$. It is obvious that the separation efficiencies of $45^{\circ}$ and $50^{\circ}$ were much better than those of $35^{\circ}$ because the gas volume fraction in the settling zone was almost zero under the angle of $45^{\circ}$ and $50^{\circ}$. The less gas that entered into the settling zone corresponded to a better separation. Therefore, the suitable angle for the inclined plate is $45^{\circ}-50^{\circ}$ for the CIBR [21].

\section{Simulation of the Residence Time Distribution by CFD}

In this study, the discrete phase model of the steady state was used to simulate the residence time distribution in the aeration period of the CIBR. After the flow field of the reactor was calculated, the characteristic, incidence and quantity of discrete phase were set. The residence time of each particle can be obtained by solving the diffusion equation to track particles. This can be used to calculate the residence time distribution function.

The quantity of incident particles was set as 4000 and the incident port was set at the water inlet of the reactor. Two outlet weirs of settling zone were set to the "escape" boundary conditions. The orbit calculation of a given particle stops when the particle arrives within one of the outlet boundaries. This indicates that the particle has left the reactor. Other boundaries (gas inlet, wall, etc.) were set to a "reflect" boundary condition. The particle hitting these boundaries will rebound with a corresponding change in momentum. The rebound coefficient used a default value of 1 . The physical properties of the particles are the same as water. In order to compare the simulation results with the results of tracer tests, the selected time point and the maximum count time were set consistently with the experimental research, wherein the quantity of particles varied with time [22-23]. A comparison of the simulation results and the experimental results was conducted (Fig. S1).

As shown in Fig. S1, the simulation results were consistent with the experimental results. The deviations of $92.6 \%$ numerical points were less than $20 \%$ between the simulation calculation and experimental study, while 
the remaining $7.4 \%$ of numerical points deviated by just $20.8 \%-21.5 \%$. The main deviation originated from the system error of the reactor model, the calculation error of mathematical model and the experiment operating error [24-25]. Hence, the simulation results are considered to be reliable.

\section{Conclusions}

In this study, the velocity felid, gas distribution, pressure felid, and turbulent energy of the flow regime within the novel CIBR were demonstrated by CFD. The CFD results further showed that increasing the aperture sizes of the below diversion hole from $2 \mathrm{~cm}$ to $8 \mathrm{~cm}$ could effectively enhance the solid-liquid separation and the treatment efficiency. Furthermore, when the angle of the inclined plate increased from $35^{\circ}$ to $45^{\circ}$ and further to $50^{\circ}$, the liquid velocity and gas holdup increased significantly in the three-phase separation zone, but decreased gradually in the settling zone, which improved gas-liquid separation in the CIBR. Hence, the suitable angle was $45^{\circ}-50^{\circ}$. The findings of this study could contribute to the structure optimization of biological reactor and the extensive application of CIBR for sewage treatment.

\section{Acknowledgments}

This research was funded by the National Key Research and Development Program of China (No. 2016YFC0400704) and the Three Gorges Base Development, Co. Ltd (JD-ZC-FW-20-003).

\section{Declaration of Competing Interest}

The authors declare that they have no known competing financial interests or personal relationships that could have appeared to influence the work reported in this paper.

\section{References}

1. LI C.L., XU Y.Y., LIU M., HU Y.M. HUANG N., Wu W. Modeling the impact of urban three-dimensional expansion on atmospheric environmental conditions in an old industrial district: a case study in Shenyang, China. Pol. J. Environ. Stud., 29 (5), 3171, 2020.

2. KOC C., KOC A.B., GOK F.C., DURAN H. Sustainable water harvesting from the atmosphere using solar-powered thermoelectric modules. Pol. J. Environ. Stud., 29 (2), 1197, 2020.

3. MOULLEC Y.L., GENTRIC C., POTIER O., LECLERC J.P. CFD simulation of the hydrodynamics and reactions in an activated sludge channel reactor of wastewater treatment. Chem. Eng. Sci., 65 (1), 492, 2010.
4. GRESCH M., ARMBRUSTER M., BRAUN D., GUJER W. Effects of aeration patterns on the flow field in wastewater aeration tanks. Water Res., 45 (2), 810, 2011.

5. FAYOLLE Y., COCKX A., GILLOT S., ROUSTAN M., HEDUIL A. Oxygen transfer prediction in aeration tanks using CFD. Chem. Eng. Sci., 62 (24), 7163, 2007.

6. JOHNSON C., NATARAJAN V., ANTONIOU C. Verification of energy dissipation rate scalability in pilot and production scale bioreactors using computational fluid dynamics. Biotech. Progress, 30, 760, 2014.

7. SHAHROKHI M., ROSTAMI F., SAID M.A.M. Numerical modeling of baffle location effects on the flow pattern of primary sedimentation tanks. Appl. Math. Model., 37 (6), 4486, 2013.

8. LIU L.X., ZHANG B.P., WU X.H., YAN G., LU X.J. Simultaneous removal of nitrogen and phosphorous from municipal wastewater using continuous-flow integrated biological reactor. J. Environ. Eng., 134, 169, 2008.

9. CHENG H.Y., YAN Y.N., YI X., WANG J., XU, W.L., NIE H.S. Initial start-up characteristics of anaerobic ammonium oxidation in a UASB reactor. Pol. J. Environ. Stud., 29 (3), 2081, 2020.

10. LONG X.Y., TANG R., ZHAN B., FANG Z.D., XIE C.X., LI Y.Q. Biological nitrogen removal in a flow-separating biochemical reactor with coral sand. Pol. J. Environ. Stud., 28 (5), 3767, 2019.

11. ZHONG Z.X., WU X.H., GAO L., LU X.J., ZHANG B.P. Efficient and microbial communities for pollutant removal in a distributed-inflow biological reactor (DBR) for treating piggery wastewater. RSC Adv., 6, 959878, 2016.

12. ZOUBEIK M., SALAMA A., HENNI A. A novel antifouling technique for the crossflow filtration using porous membranes: Experimental and CFD investigations of the periodic feed pressure technique. Water Res., 146, $159,2018$.

13. SANCHEZ F., REY H., VIEDMA A., NICOLAS P.F., KAISER A.S., MARTÍNEZ M. CFD simulation of fluid dynamic and biokinetic processes within activated sludge reactors under intermittent aeration regime. Water Res., 139 (1), 47, 2018.

14. WANG X., DING J., GUO W.Q., REN N.Q. A hydrodynamics-reaction kinetics coupled model for evaluating bioreactors derived from CFD simulation. Bioresource Techn., 101, 9749, 2010.

15. BRANNOCK M., WANG Y., LESLIE G. Mixing characterization of full-scale membrane bioreactors: CFD modelling with experimental validation. Water Res., 44, 3181, 2010.

16. XU Q., WAN Y.L., WU Q.X., XIAO K.K., YU W.B., LIANG S., ZHU Y.W., HOU H.J., LIU B.C., HU J.P., YANG Y., YANG J.K. An efficient hydrodynamicbiokinetic model for the optimization of operational strategy applied in a full-scale oxidation ditch by CFD integrated with ASM2. Water Research, 193, 1, 2021.

17. BRANNOCK M., LESLIE G., WANG Y., BUETEHORN $\mathrm{S}$. Optimizing mixing and nutrient removal in membrane bioreactors: CFD modelling and experimental validation. Desalination, 250, 815, 2010.

18. BACH C., YANG J.F., LARSSON H., STOCKS S.M., GERNAEY K.V., ALBAEK M.O., KRÜHNE U. Evaluation of mixing and mass transfer in a stirred pilot scale bioreactor utilizing CFD. Chem. Eng. Sci., 171, 19, 2017. 
19. ZHANG J., CHEN X.G., LIU J.S., HUANG B., XU M. Structural characteristics of a spiral symmetry stream anaerobic bioreactor based on CFD. Biochemical Eng. J., 137, 50, 2018.

20. RAHIMI M.J., SITARAMAN H., HUMBIRD D., STICKEL J.J. Computational fluid dynamics study of fullscale aerobic bioreactors: Evaluation of gas-liquid mass transfer, oxygen uptake, and dynamic oxygen distribution. Chemical Engineering Research and Design, 139, 283, 2018.

21. XU Q., YANG J.K., HOU H.J., HU Y.C., LIANG S., XIAO K.K., WU X., LIU B.C., HU J.P., HU J.K., YANG C.Z. Simulation on flow field and gas hold-up of a pilot-scale oxidation ditch by using liquid-gas CFD model. Water Sci. \& Tech., 78.9, 1956, 2018.

22. ZHANG X., LI Y.R., WU M.R., PANG Y., HAO Z.B., HU M., QIU R.L., CHEN, Z.H. Enhanced adsorption of tetracycline by an iron and manganese oxides loaded biochar: Kinetics, mechanism and column adsorption. Bioresource Technology, 320, 124264, 2020.

23. HE Q.L., ZHOU J., WANG H.Y., ZHANG J., WEI L. Microbial population dynamics during sludge granulation in an $\mathrm{A} / \mathrm{O} / \mathrm{A}$ sequencing batch reactor. Bioresource Technology, 214, 1, 2016.

24. LITTLETON H.X., DAIGGER G.T., STROM P.F. Application of CFD to Closed-Loop Bioreactors: I. characterization and simulation of fluid-flow pattern and oxygen transfer. Water Environ. Res., 79 (6), 600, 2007.

25. WRIGHT M.R., BACH C., GERNAEY K.V., KRÜHNE $\mathrm{U}$. Investigation of the effect of uncertain growth kinetics on a CFD based model for the growth of S.cerevisiae in an industrial bioreactor. Chem. Eng. Res. and Des., 140, 12, 2018.

\section{Supplementary Material}

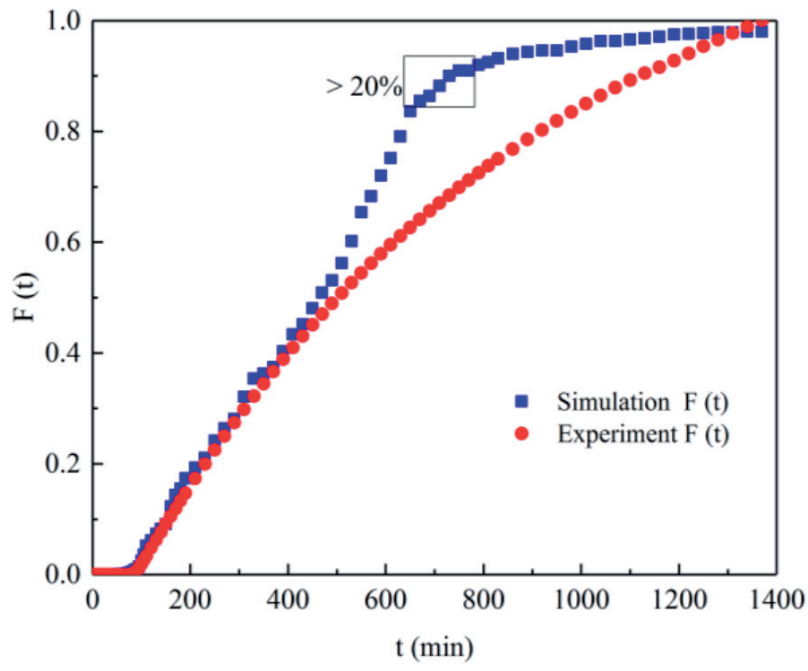

Fig. S1. The comparison between $\mathrm{F}(\mathrm{t})$ of simulation and the experiment. 